\title{
Electrical Conductivity of Water Treated by Spark Discharge
}

\author{
Alexander A. Belov', Alexey N. Vasilyev², Andrey A. Musenko ${ }^{3}$ \\ ${ }^{1-3}$ Federal Scientific Agroengineering Center VIM, Russia
}

\begin{tabular}{l} 
Article Info \\
\hline Article history: \\
Received Mar 31, 2019 \\
Revised Jun 28, 2019 \\
Accepted Jul 19, 2019 \\
\hline Keyword: \\
Electrohydraulic effect \\
Electromagnetic field \\
High voltage \\
Ionization \\
Pulse energy
\end{tabular}

\begin{abstract}
Electrical conductivity is an electrophysical characteristic, which is considered to be an estimate of the ability of substances to miss electrical current. Achieving the result of the formation of electrohydraulic discharges in water directly depends on the magnitude of the electrical conductivity, which argues the relevance of the topic. The paper presents the results of a study of the influence of electrohydraulic treatment on the change in the electrical conductivity of water. As a result of identifying significant factors influencing the process, rational parameters of the technological mode of electrohydraulic treatment of distilled, lake and tap water were selected. Curves of functional dependences of electrical conductivity on the number of spark high-voltage pulsed discharges are constructed. The relationship between the electrical conductivity of water and the modes of electrohydraulic effects is established.
\end{abstract}

Copyright (c) 2019 Institute of Advanced Engineering and Science. All rights reserved.

\section{Corresponding Author:}

Alexander A. Belov,

Federal Scientific Agroengineering Center VIM,

109428, 1st Institute Passage, 5, Moscow, Russia.

Email: belalexan85@gmail.com

\section{INTRODUCTION}

Electrohydraulic (EH) processing in a liquid medium is carried out to achieve different results and, as a result, is applied quite widely in various industries and in agriculture. This disinfection of wastewater, increasing the concentration of nitrogen compounds assimilated by plants, removing scale formation in heat exchangers and others [1-5]. In addition, there are studies of the decomposition of atrazine herbicide in aqueous solution as a result of electrohydraulic treatment, which can be used to restore chemically contaminated soil due to the unfair work of farmers, which emphasizes the environmental effect [6]. Electrohydraulic treatment of water is accompanied by the following electrophysical characteristics of the process: high and ultra-high impulse hydraulic pressures; mechanical resonance phenomena; intense pulsed light, heat, ultraviolet radiation; multiple ionization of compounds and elements contained in a liquid [7]. To study these effects, quite expensive instrumentation technical means of measurement are required. However, all of the above factors are interrelated. Therefore, the authors propose a method of integrated assessment of electrophysical characteristics based on studies of the dynamics of changes in specific electrical conductivity (hereinafter referred to as electrical conductivity) by identifying patterns by which the change in electrical conductivity will correspond to the change in a number of electrophysical parameters. This will serve to interpret the variation of technological regimes and possible constructive improvements of the installation in order to increase the achievable EH-effects [8]. In this regard, the purpose of research is to establish the patterns and relationships of changes in conductivity as a result of EH-processing.

\section{RESEARCH METHOD}

The article conducts experimental studies to identify changes in the electrical conductivity of water as a result of EH-treatment. Applied equipment and methods for measuring the conductivity of water: appendix to certificate No. 58191 on the approval of the type of measuring instruments using the ATLANT 1200 conductometric multi-channel fluid analyzer. A sifting experiment is carried out based on the method of Plackett-Berman. The method of random balance is used to isolate insignificant factors influencing the electrohydraulic process. 


\section{RESULTS AND DISCUSSION}

The electrical conductivity of water characterizes its ability to conduct electrical current. In this article, the term water refers to both distilled and tap and lake water. However, tap and lake waters are not chemically pure; in this connection, the definition of aqueous solutions will be more accurate. Aqueous solutions are created either industrially, in which case they can be considered artificial, or the surrounding nature, then they can be considered waters from sources of natural origin. Aqueous solutions are used for various purposes to carry out any processes. Therefore, aqueous solutions can be considered working. In addition to water molecules, they contain ions of mineral salts and organic substances, which mainly determine the electrical conductivity of water and working aqueous solutions. According to the level of salts and substances of organic origin dissolved in water, it is possible to judge the possibility of creating an electrohydraulic effect. Electrical discharges during EH-processing are a consequence of the circuit closure and the flow of electric current between the electrodes. Consequently, the electrical conductivity of water and aqueous solutions is the electrophysical factor that can serve as a characteristic of all the basic properties of the EH-treatment process.

For experimental studies of changes in the electrical conductivity of water as a result of EH-treatment, an EH-installation with a spark gap was used. The EH-installation includes a sinusoidal voltage source of 220 $\mathrm{V}$. The transformer increases the input voltage, which is stored in capacitors. There is an autotransformer to regulate the voltage value and correctly supply it to the load. Upon reaching a voltage sufficient to break the forming gap and the working gap, a spark is generated.

An analytical review of the collected theoretical information on the topic under consideration and experiments carried out taking into account the theoretical foundations of the generation and propagation of electromagnetic waves in the high-voltage range in water shows that the process of electrohydraulic processing is characterized by a large number of factors. However, only a small part of them has a significant impact on the result. Therefore, it is important to determine the most important factors affecting the yield of assimilable nutrient forms during EH-treatment [9]. In addition, in the process under consideration, it is possible to change the operating modes of the installation. The proposed impact parameters and modes of operation of the object are considered as factors, the size and level of which mainly determine and change the output results of the experiments. Modeling of factors influencing the process of EH-processing is carried out in two ways. The first method is based on the plan of Plackett-Berman and is designed to eliminate non-essential factors. The second method is based on the use of the random balance method to isolate the most significant factors influencing the process of EH-exposure in aqueous solutions with ionic conductivity.

A sifting experiment based on the plan of Plackett-Berman was conducted by constructing a mathematical model. The following stages of the experiment were solved:

- identified factors that influence in varying degrees on the system;

- factors were analyzed;

- these factors were systematized according to the form and method of management by designating their levels;

- matrix of sifting experiment was developed.

Table 1. Factors affecting the system

\begin{tabular}{|c|c|c|c|c|}
\hline \multirow{2}{*}{$\begin{array}{l}\text { No. } \\
\text { p/p }\end{array}$} & \multirow{2}{*}{$\begin{array}{l}\text { Classification of factors } \\
\text { and objective function }\end{array}$} & \multirow{2}{*}{$\begin{array}{l}\text { Decipherment of factors and objective } \\
\text { function }\end{array}$} & \multicolumn{2}{|c|}{ Levels of variation } \\
\hline & & & -1 & +1 \\
\hline 1 & $X 1$ & The magnitude of the applied voltage, $\mathrm{kV}$ & 10 & 70 \\
\hline 2 & $X 2$ & The duration of the experiment, $\mathrm{s}$ & 60 & 600 \\
\hline 3 & $X 3$ & Capacity of storage capacitors, $\mu \mathrm{F}$ & 0.025 & 0.2 \\
\hline 4 & $X 4$ & Volume of test chamber, 1 & 1 & 5 \\
\hline 5 & $X 5$ & Pulse frequency, $\mathrm{Hz}$ & 1 & 50 \\
\hline 6 & X6 & Pulse energy, $\mathrm{J}$ & 1.25 & 490 \\
\hline 7 & $X 7$ & Electrode area, $\mathrm{mm}^{2}$ & 1 & 2500 \\
\hline 8 & $X 8$ & Fictitious factor & - & - \\
\hline 9 & $x 9$ & Number of pulses, pcs. & 10 & 300 \\
\hline 10 & $X 10$ & The inductance of the discharge circuit, $\mu \mathrm{H}$ & 50 & 200 \\
\hline 11 & $X 11$ & Water source (lake, sea) & lake & sea \\
\hline 12 & $X 12$ & Electrode material (copper, titanium) & copper & titanium \\
\hline 13 & $X 13$ & Fictitious factor & - & - \\
\hline 14 & $X 14$ & Electrode shape, (needle, disk) & needle & disk \\
\hline 15 & $X 15$ & Fictitious factor & - & - \\
\hline 16 & $Z 1$ & Solution temperature, ${ }^{\circ} \mathrm{C}$ & 0 & 50 \\
\hline 17 & $Z 2$ & Ambient temperature, ${ }^{\circ} \mathrm{C}$ & -20 & +20 \\
\hline 18 & $Y$ & Nitrogen yield, mg / 1 & 10 & 1500 \\
\hline
\end{tabular}


The variance of observational errors was estimated by introducing fictitious factors into the plan. Three fictitious factors were added to the plan with the aim of forming an experiment plan of type $\mathrm{N}=16$. The effects of these dummy variables will be zero only if there are no interactions and the measurements are absolutely accurate. Since this is not usually done in practice, they can be used to estimate the variance of observations. Thus, significant factors were identified in accordance with Table 1.

Due to certain design features of the installation, it is not possible to vary the temperature of the solution and the environment at this stage of the experiments. In this regard, the factors $Z 1$ and $Z 2$ in the first approximation are neglected. Based on the data in table 1, the authors compose a matrix of the plan of PlackettBerman with factors in coded units and with objective function in physical units in accordance with Table 2.

Table 2. The matrix of the plan of Plackett-Berman

\begin{tabular}{|c|c|c|c|c|c|c|c|c|c|c|c|c|c|c|c|c|}
\hline \multirow{2}{*}{$\begin{array}{l}\text { No. } \\
\mathrm{p} / \mathrm{p}\end{array}$} & \multicolumn{15}{|c|}{ Factor levels } & \multirow{2}{*}{$\begin{array}{c}\text { Response } \\
Y\end{array}$} \\
\hline & $X 1$ & $X 2$ & $X 3$ & $X 4$ & $X 5$ & $X 6$ & $X 7$ & $X 8$ & $X 9$ & $X 10$ & $X 11$ & $X 12$ & $X 13$ & $X 14$ & $X 15$ & \\
\hline 1 & + & + & + & + & - & + & - & + & + & - & - & + & - & - & - & 1500 \\
\hline 2 & + & + & + & - & + & - & + & + & - & - & + & - & - & - & + & 390 \\
\hline 4 & + & - & + & - & + & + & - & - & + & - & - & - & + & + & + & 1500 \\
\hline 5 & - & + & - & + & + & - & - & + & - & - & - & + & + & + & + & 25 \\
\hline 6 & + & - & + & + & - & - & + & - & - & - & + & + & + & + & - & 97 \\
\hline 9 & + & - & - & + & - & - & - & + & + & + & + & - & + & - & + & 540 \\
\hline 10 & - & - & + & - & - & - & + & + & + & + & - & + & - & + & + & 413 \\
\hline 11 & - & + & - & - & - & + & + & + & + & - & + & - & + & + & - & 319 \\
\hline 12 & + & - & - & - & + & + & + & + & - & + & - & + & + & - & - & 108 \\
\hline 13 & - & - & - & + & + & + & + & - & + & - & + & + & - & - & + & 365 \\
\hline
\end{tabular}

Processing of experimental results [10]:

1. The calculation of the effects of individual factors.

The estimate of the effect of $B_{i}$ is equal to the difference between the sums of the values of the objective function for factor $x_{i}$ at levels +1 and -1 divided by $N / 2$ :

$$
B_{i}=\frac{\sum_{j=1}^{N} y^{j} x_{i}^{j}}{N / 2}
$$

In accordance with (1) are:

$B_{i 1}=392.25 ; B_{i 2}=33 ; B_{i 3}=299.75 ; B_{i 4}=-28.75 ; B_{i 5}=44 ; B_{i 6}=197 ; B_{i 7}=-250.25 ; B_{i 8}=32.5 ; B_{i 9}=593.5$;

$B_{i 10}=-247.5 ; B_{i 11}=-215.75 ; B_{i 12}=-29.25 ; B_{i 13}=-40.75 ; B_{i 14}=-40.25 ; B_{i 15}=44.5$.

The values of $a_{i}$ are equal to half of the respective effect estimates.

Table 3 shows the levels of factors and the effects of $B_{i}$ (or the coefficients $a_{i}$ ), which are determined in accordance with expression 1

2. Check the significancy of the parameters.

To identify significant factors, $t$-criterion is used and the condition is checked:

$$
\left|a_{i}\right| \geq t_{c r} \cdot S_{i}
$$

where $t_{c r}$-critical value of the $t$-distribution for the significance level $\alpha$ and $\varphi$ degrees of freedom; $S_{i}{ }^{2}$-estimate of the dispersion of the coefficient $a_{i}$.

The variance of observation errors is estimated using special experiments, introducing into the plan fictitious factors from $x_{l+1}$ to $x_{N-1}$ in accordance with the expression:

$$
S_{l}^{2}=\frac{4 k\left(a_{l+1}^{2}+a_{l+2}^{2}+\ldots+a_{N-1}^{2}\right)}{4 k-l-1} .
$$

Regarding the structuring of fictitious factors and in accordance with (3), for calculating the variance of observation errors, the expression is obtained:

$$
S_{l}^{2}=\frac{4 k\left(a_{8}^{2}+a_{13}^{2}+a_{15}^{2}\right)}{4 k-l-1}
$$


where $k=4, l=12$.

In accordance with (4) determine

$$
S_{l}^{2}=16 \cdot 391.421875
$$

The variance of the estimates of the coefficient $a_{i}$ is determined from the expression:

$$
S_{i}^{2}=\frac{S_{l}^{2}}{4 \cdot k}
$$

Thus, in accordance with (5) receive

$$
S_{i} \approx 19.78 \text {. }
$$

Taking into account $\alpha=0.05$ and $\varphi=3$ from the table of $t$-distribution (distribution according to the Student's $t$-test) find $t_{\kappa p}=3.18$.

The significancy of the indexes is checked in accordance with (2)

$$
\left|a_{i}\right| \geq 3.18 \cdot 19.78 \approx 62.9 .
$$

As a result of the significance test, the marginal, that is, significant and insignificant factors that have a certain impact on the target output function in accordance with the initial indicators, were identified.

In order to determine the estimates of the influence of each of the essential factors and for their more visual analysis, their distribution is compiled according to the degree of influence on the target value of the yield of nutrients in water in accordance with the diagram in figure 1.

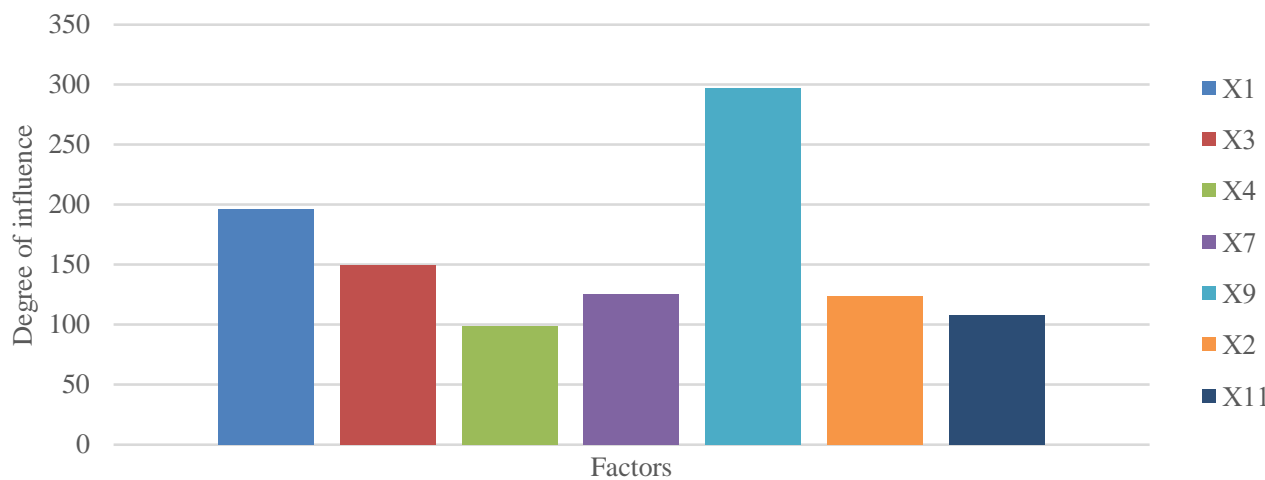

Figure 1. Distribution of factors according to the degree of their influence on the target value

As a result of the sifting experiment based on the plan of Plackett-Berman, it was revealed that the significant factors affecting the yield of nitrate forms of nitrogen are:

$-X 1$ the magnitude of the applied voltage;

- X3 capacity of storage capacitors;

- X6 pulse energy;

$-X 7$ electrode area;

- X9 number of pulses;

- X10 the inductance of the discharge circuit;

$-X 11$ water source.

Of the above, the most significant factors are:

$-X 1$ the magnitude of the applied voltage;

- X3 capacity of storage capacitors;

- $X 9$ number of pulses.

The random balance method was used to distribute significant factors. According to this method, significant factors are singled out from a large set of variables. They also take into account their paired interactions. It is assumed that of the entire flow of factors only their insignificant or significant part, which will be established as a result of the experiment, will probably have a significant impact on the output dependent value. Impact parameters and operating modes of the installation with a minor impact can be considered the so-called "noise".

The mathematical model includes 15 linear effects and 105 paired interactions. The planning edge areas of the experiment were developed for 15 process-influencing factors, where $x 1$ - is the level of applied voltage; $x 2$ - the duration of the experiment; $x 3$ - inductance; $x 4$ - material test chamber; $x 5$ - the area of the electrodes; $x 6$ - is the number of pulses; $x 7$ - is the volume of the test chamber; $x 8$ - electrode material; $x 9$ is the pulse frequency; $x 10$ - the shape of the electrodes; $x 11$ - is the pulse energy; $x 12$ - capacity of storage 
capacitors; $x 13$ - type of aqueous solution; $x 14-$ is the temperature of the aqueous solution; $x 15$ - ambient temperature. Factors vary according of two levels.

In accordance with Table 3, the boundaries of the planning area are defined.

Table 3. Boundaries of the planning area of the experiment for the 15 influence factors studied

\begin{tabular}{lllllllllllllllll}
\hline Factors & & $\mathrm{x}_{1}{ }^{*}$ & $\mathrm{x}_{2}{ }^{*}$ & $\mathrm{x}_{3}{ }^{*}$ & $\mathrm{x}_{4}{ }^{*}$ & $\mathrm{x}_{5}{ }^{*}$ & $\mathrm{x}_{6}{ }^{*}$ & $\mathrm{x}_{7}{ }^{*}$ & $\mathrm{x}_{8}{ }^{*}$ & $\mathrm{x}_{9}{ }^{*}$ & $\mathrm{x}_{10}{ }^{*}$ & $\mathrm{x}_{11}{ }^{*}$ & $\mathrm{x}_{12}{ }^{*}$ & $\mathrm{x}_{13}{ }^{*}$ & $\mathrm{x}_{14}{ }^{*}$ & $\mathrm{x}_{15}{ }^{*}$ \\
\hline Levels & +1 & 70 & 600 & 20 & $\mathrm{Ti}$ & 2500 & 300 & 5 & $\mathrm{Cu}$ & 50 & $\mathrm{C}$ & 490 & 0.2 & $\mathrm{~L}$ & 50 & 20 \\
& -1 & 10 & 60 & 5 & $\mathrm{Fe}$ & 1 & 100 & 1 & $\mathrm{Ti}$ & 1 & $\mathrm{~N}$ & 1.25 & 0.025 & $\mathrm{~S}$ & 0 & 0 \\
\hline
\end{tabular}

To construct the plan of the experiment, the mixing of randomly formed samples, that is, the set of test cases obtained on the basis of fractional plans, is used. The resulting factors are structured into the following groups.

1. $\mathrm{x} 1, \mathrm{x} 2, \mathrm{x} 3, \mathrm{x} 4$

2. $\mathrm{x} 5, \mathrm{x} 6, \mathrm{x} 7, \mathrm{x} 8$.

3. $\mathrm{x} 9, \mathrm{x} 10, \mathrm{x} 11, \mathrm{x} 12$.

4. $\mathrm{x} 13, \mathrm{x} 14, \mathrm{x} 15$.

An experiment plan of type $2^{4}$ is chosen. Through a random sampling of numerical values from the matrix of the plan $2^{4}$, rows are marked by a random method. This is done individually for each of the composed groups of factors. For 16 experiments, 16 lines are selected. For this sample, the following sequence of lines are obtained:

- group 1: 10,6, 3,16, 4,15, 14,1, 5,9, 7,13, 2,8, 12,11;

- group 2: 13,3, 7,16, 2,9, 2,16, 6,12, 13,7, 9,12, 3,6;

- group a $3: 5,10,15,16,3,4,15,4,6,9,9,3,16,5,6,10$;

- group 4: 7,15, 11,8, 16,3, 5,13, 4,12, 6,2, 2,1, 14,9.

Next, a plan matrix is developed that takes into account the output function.

The next stage is the construction of a scatterplot. On the dependency graph, the values of the resulting function are plotted over each of the 15 factors considered in accordance with the scatter diagram in figure 2 . Both levels of varying factors +1 and -1 are noted and medians are found, that is, the mean lines of the factors studied. The criterion of the degree of influence of the corresponding factor is determined by the difference between the medians. The most significant impact has factor $x 4$. This follows from the analysis of chart. The visual identification of dominant factors by the magnitude of the medians is allowed to be replaced by a method based on the determination of the number of "peculiar points".

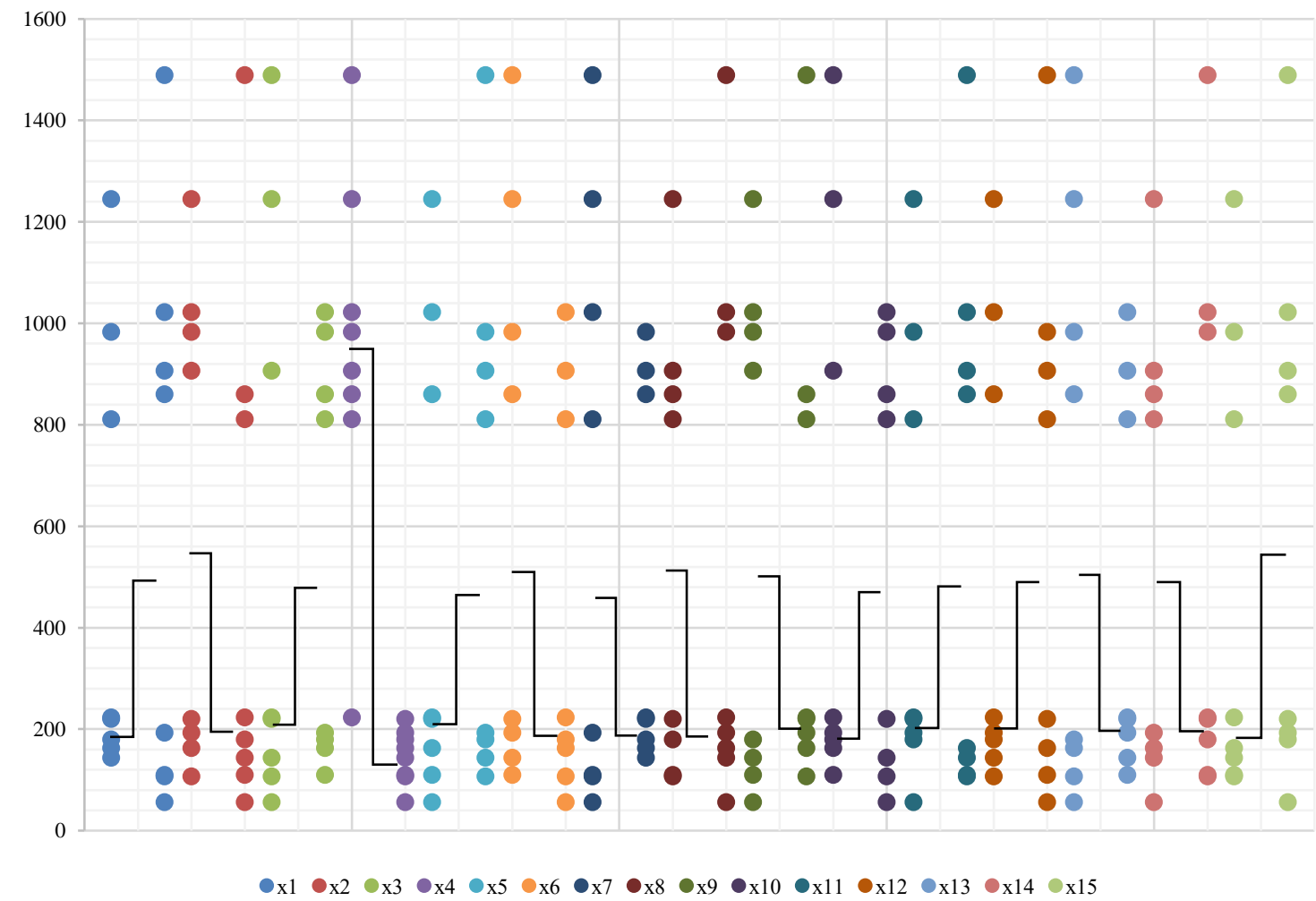


Figure 2. The scatter diagram for 15 factors

"Peculiar points" are the definitions of the output function for the upper maximum level of the factor $\left(x_{i}=+1\right)$, which are less than the smallest or greater than the largest value corresponding to another level $\left(x_{i}=\right.$ -1). The combination of such graphic points is allowed to characterize the importance of factors.

The estimation of contributions is determined by the average value of the output function, for which the selected factor $x_{4}$ is located at a high level of +1 . Then, the average value of the output function at a low level of -1 is subtracted from it. The coefficients of the experiment plan are determined similarly. Thus, the estimation of the factor $\mathrm{x}_{4}$ is equal to $B_{4}{ }^{l}=795.875$. The value $B_{4}{ }^{l}$ allows you to get a parameter estimate $a_{4}{ }^{l}$ $=B_{4}{ }^{1} / 2=397.9375 \approx 398$.

To find other significant factors, the influence of factor $x_{4}$ on the output function is eliminated. For this purpose, the value of $2 \cdot a_{4}{ }^{l}=796$ is subtracted from all output functions for which $\mathrm{x} 4$ was at the level of +1 . Thus, the effect of the factor $x_{4}$ on these quantities is terminated. Following this action, a newly calculated vector of experimental results is formed. In the second scatter diagram, the $x_{4}$ factor already interrupts to influence and the factors $x_{2}, x_{13}, x_{14}$ have the greatest influence (the second and subsequent scatter diagramb are not shown, the construction is carried out by analogy with the first).

The next step is to assess the contributions of $a_{2}, a_{13}, a_{14}$ for factors $x_{2}, x_{13}, x_{14}$. For each group of numerical values is the average value of the output function. Estimates of the contributions of factors are calculated by the differences between the sums of average values for high and low levels according to the following expression:

$$
B_{2}^{2}=\frac{y_{3}^{m}+y_{4}^{m}+y_{5}^{m}+y_{6}^{m}+y_{11}^{m}+y_{14}^{m}+y_{15}^{m}+y_{16}^{m}}{8}-\frac{y_{1}^{m}+y_{2}^{m}+y_{7}^{m}+y_{8}^{m}+y_{9}^{m}+y_{10}^{m}+y_{12}^{m}+y_{13}^{m}}{8},
$$

where $m=2$.

$B_{13}{ }^{2}$ and $B_{14}{ }^{2}$ are defined similarly. Estimates of the coefficients are calculated by the above expression. The values of the estimates of contributions and ratios thus more clearly allow us to characterize the degree of significance of factors than the difference in medians. For the estimates of the coefficients $a_{2}, a_{13}$, $a_{14}$, the following numerical values were obtained:

$a_{2}^{2}=60.43 ; a_{13}^{2}=90.81 ; a_{14}^{2}=2.81$.

The numerical value of the coefficient estimate $a_{14}{ }^{2}=2.81$ compared with the other two. Therefore, further calculation will be carried out in case of removal only from the influence of factors $x_{2}$ and $x_{13}$. This is achieved by subtracting from those output functions $y^{2}$, for which $x_{2}=+1$ and $x_{13}=+1$, the values of $B_{2}{ }^{2}$ and $B_{13}{ }^{2}$ are correspondingly. Then a vector of results $y^{3}$ is obtained and a new scatter diagram is developed, which shows that factors $x_{6}$ and $x_{7}$ have the greatest influence. Further calculation of parameter estimates is carried out according to the above method.

Ultimately, the following estimates are determined:

$a_{1}^{5}=20.5 ; a_{2}^{2}=60.43 ; a_{4}{ }^{1}=398 ; a_{5}^{4}=-64.38 ; a_{6}^{3}=-11.5 ; a_{7}^{3}=-4.9 ; a_{11}^{4}=-55.69 ; a_{12}{ }^{5}=55.7 ;$ $a_{13}{ }^{2}=90.81 ; a_{14}{ }^{2}=2.81 ; a_{15}{ }^{4}=-71.31$.

The final stage is to test the significancy of the coefficients on the basis of the $t$-criterion. For example, we calculate the verification of the significance of the coefficient $a_{l}$ :

$$
\begin{aligned}
& S_{1}^{2}=\frac{(310-197)^{2}+(562-197)^{2}+(-190-197)^{2}+(109-197)^{2}}{3}=101169, \\
& S_{2}^{2}=58059, S_{3}^{2}=36088, S_{4}^{2}=19875, \\
& S_{F}^{2}=1560, \\
& S^{2}=\frac{1}{16} \cdot 1560 \cdot \frac{4}{4}=97.5, \\
& S=9.9, \varphi=12 .
\end{aligned}
$$

When $\alpha=0.05$, the critical value $t_{\kappa p}$ is 2.18 . In this connection, the $a_{l}$ estimate is insignificantly different from zero. This completes the definition of linear effects. Next, the most basic of pairwise interactions is highlighted.

The following pairwise interactions are significant:

$x_{1} x_{11}, x_{3} x_{10}, x_{5} x_{12}, x_{6} x_{13}, x_{8} x_{14}, x_{11} x_{15}$.

This process of highlighting the significance of a pair can continue indefinitely. Therefore, at this stage a certain stopping criterion is required. It is possible to use the $F$-criterion:

$$
F=\frac{S_{m}^{2}}{S^{2}}
$$


where $S_{m}{ }^{2}$ - is the estimate of the variance of the experimental results relative to their arithmetic average value at the r-step of the operation; $S^{2}-$ is the estimate of the variance of observation errors calculated on the basis of the results of several parallel observations. The change in the dispersions $S_{m}{ }^{2}(r)$ depending on the step number $r$ of the factor extraction procedure can be analyzed using the scatter plot. This dependence characterizes the change in the variances of the results of experiments. Following this diagram, it can be revealed that after five steps this dispersion is quite small. By repeating the experiments at one point of the plan, the estimate $s^{2}=32$ is found $(\varphi=7)$. Along with this, for $S_{m}{ }^{2}(5)=74.4\left(\varphi_{m}=12\right)$ it turns out

$$
F=\frac{74,4}{32}=2.32<3.5=F_{\text {кр }}, \alpha=0.05 \text {. }
$$

All significant factors are highlighted. This indicates that the settlement operations for this procedure can be terminated.

In the end, inconsequential factors are reasonably defined: the duration of the experiment; test chamber material; the volume of the test chamber; pulse frequency.

Thus, the results of the constructed optimization models for identifying significant and insignificant factors on the basis of two methods coincide and are correlated.

Thus, the process of electrohydraulic treatment of aqueous working solutions is influenced mainly by the magnitude of the applied voltage, the capacity of the storage capacitors and the number of pulses. The voltage and capacitance of the capacitors are interrelated factors; they can be generalized by the on the value of released energy. Therefore, the factor of the number of pulses is chosen by a variable parameter when evaluating the dynamics of electrical conductivity.

Marked design parameters of the installation. Electrode system (needle, disk) immersed in a water test sample. The electrodes are insulated from the container by a dielectric material. When choosing rational parameters, the distances between the electrodes, which affect the generated energy in the spark gap, were taken into account [11]

Three technological modes of EH-impact on water were selected using the installation. The selection bases are the minimum applied voltage to the capacitive-inductive load [12]. At this stage of the experiments, the inductance of the circuit and the capacitance are constant values due to the design features of the installation. It should be noted that for the maximum energy concentration in the discharge zone and the optimum shape and temporal characteristic of the pulse, the inductance of the circuit should be minimal [13-14]. The first technological mode is provided with the following parameters: voltage - $15 \mathrm{kV}$; storage capacitor capacitance - $0.1 \mu \mathrm{F}$; inductance - $20 \mu \mathrm{H}$; pulse energy - $11.3 \mathrm{~kJ}$; air gap - $10 \mathrm{~mm}$; working gap - $8 \mathrm{~mm}$. The pulse energy is determined by the calculation method; it is considered equal to the accumulated energy on the plates of the capacitor battery of the installation.

In the second process mode, the following parameters are accepted: voltage - $38 \mathrm{kV}$; storage capacitor capacitance - $0.1 \mu \mathrm{F}$; inductance - $20 \mu \mathrm{H}$; pulse energy - $72.2 \mathrm{~kJ}$; air gap - $13 \mathrm{~mm}$; working gap - $10 \mathrm{~mm}$.

The third process mode is characterized by the following technological parameters: voltage $-50 \mathrm{kV}$; storage capacitor capacitance - $0.1 \mu \mathrm{F}$; inductance - $20 \mu \mathrm{H}$; pulse energy - $125.0 \mathrm{~kJ}$; air gap - $20 \mathrm{~mm}$; working gap - $20 \mathrm{~mm}$.

The air and working intervals were established according to experimental observations in terms of the formation of discharge pulses with a power sufficient to achieve EH-shocks. The criteria for achieving the EHstrikes and, accordingly, ensuring the EH-effect for the processed medium were visual and acoustic characteristics. These are claps, the mechanical movement of fluid flows directed from a discharge channel, the generation of a spark discharge, in the foreign literature called plasma. In this context, the analogy is carried out with the breakdown of an air gap with a strength of $30 \mathrm{kV} / \mathrm{cm}$. The air, which is considered an insulator, is transformed into an ionized gas. That is, one can consider this phenomenon as the transition of a substance from one aggregative state to another. Initial initial conditions: the temperature of the investigated water samples was $18^{\circ} \mathrm{C}$; loading volume of the investigated water samples 2.5 liters.

Water samples were taken of three types: plumbing, distilled and lake. The basis of the choice of these particular varieties of water is their possible use as nutrient solutions in vegetable production.

The electrical conductivity of distilled water is minimal relative to tap and lake water. Samples of distilled water were obtained by the method of reverse osmosis, the initial value of electrical conductivity of $108 \mu \mathrm{S} / \mathrm{cm}$. A sample of tap water was taken from the city water supply of the South-Eastern Administrative District of Moscow, the initial value of electrical conductivity was $355 \mu \mathrm{S} / \mathrm{cm}$. A sample of lake water was taken from an open reservoir in the Moscow region, the initial value of electrical conductivity $258 \mu \mathrm{S} / \mathrm{cm}$.

It was experimentally confirmed that, due to the EH-effect from the physical properties, the electrical conductivity changes in accordance with the dynamics in Figures 3-5. 


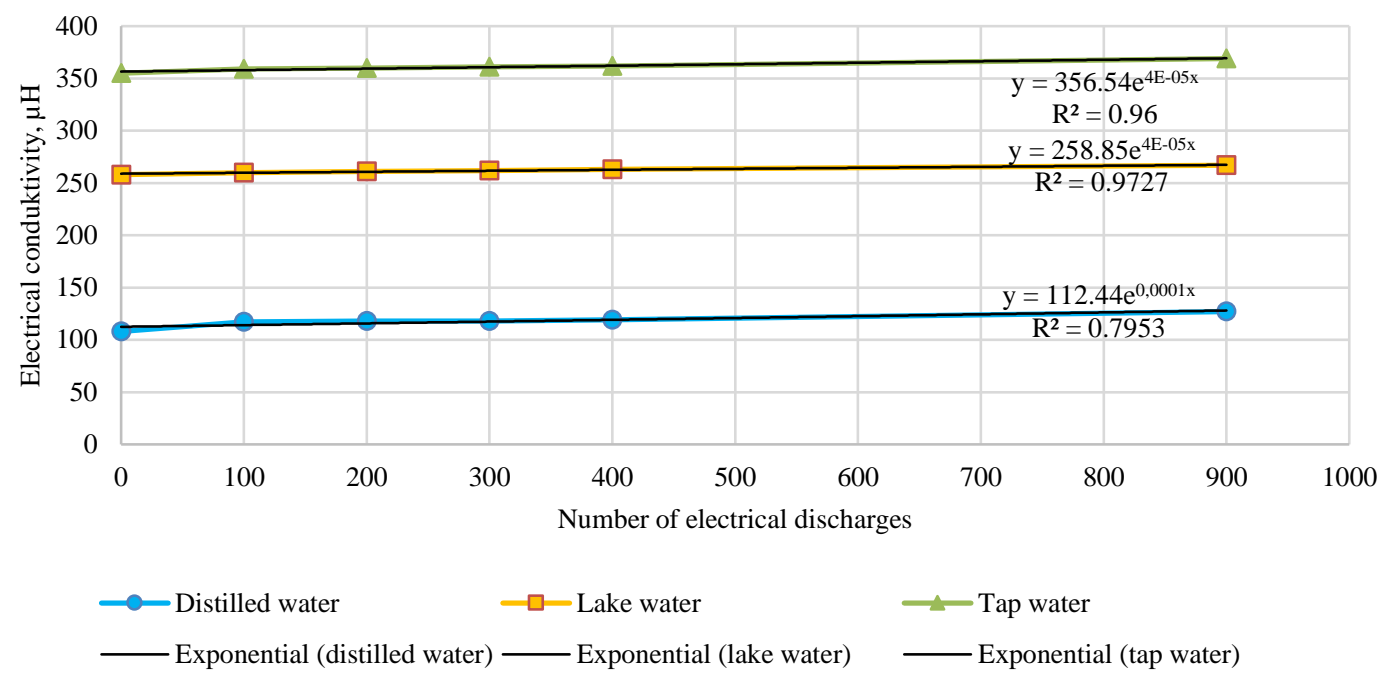

Figure 3. Dynamics of the specific conductivity of water at a voltage of $15 \mathrm{kV}$

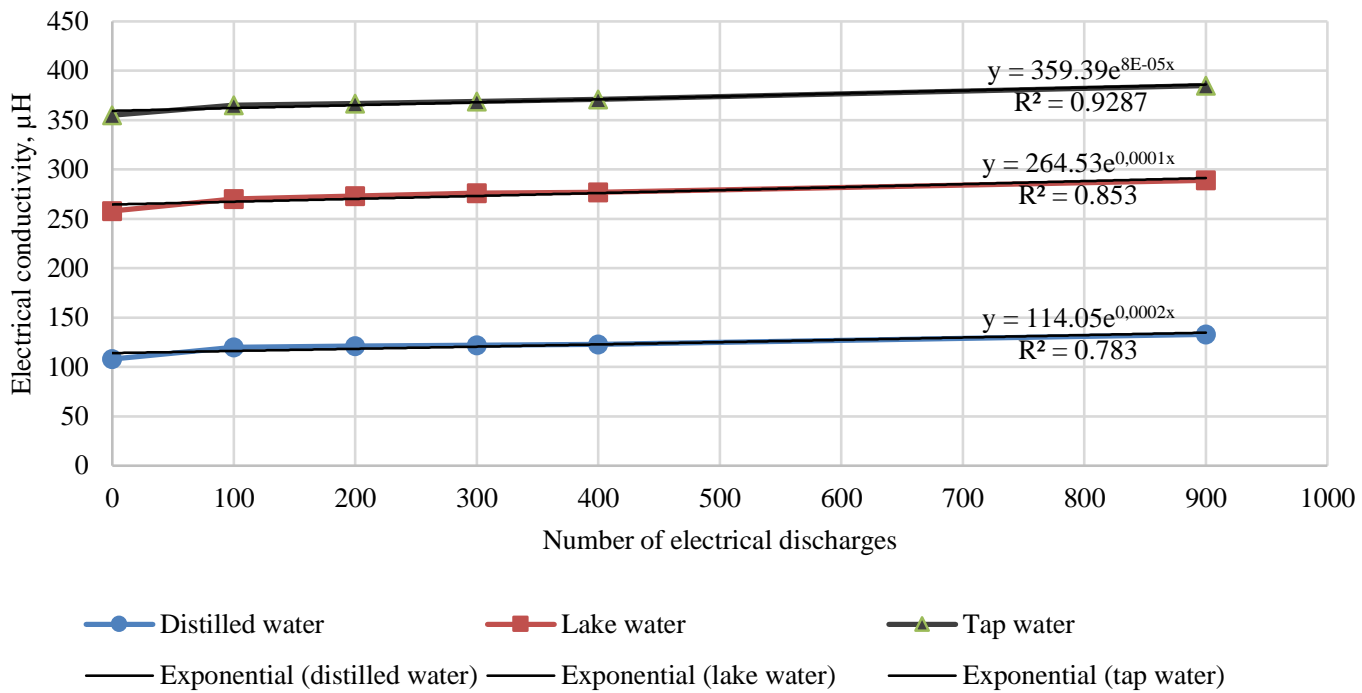

Figure 4. Dynamics of the specific conductivity of water at a voltage of $38 \mathrm{kV}$

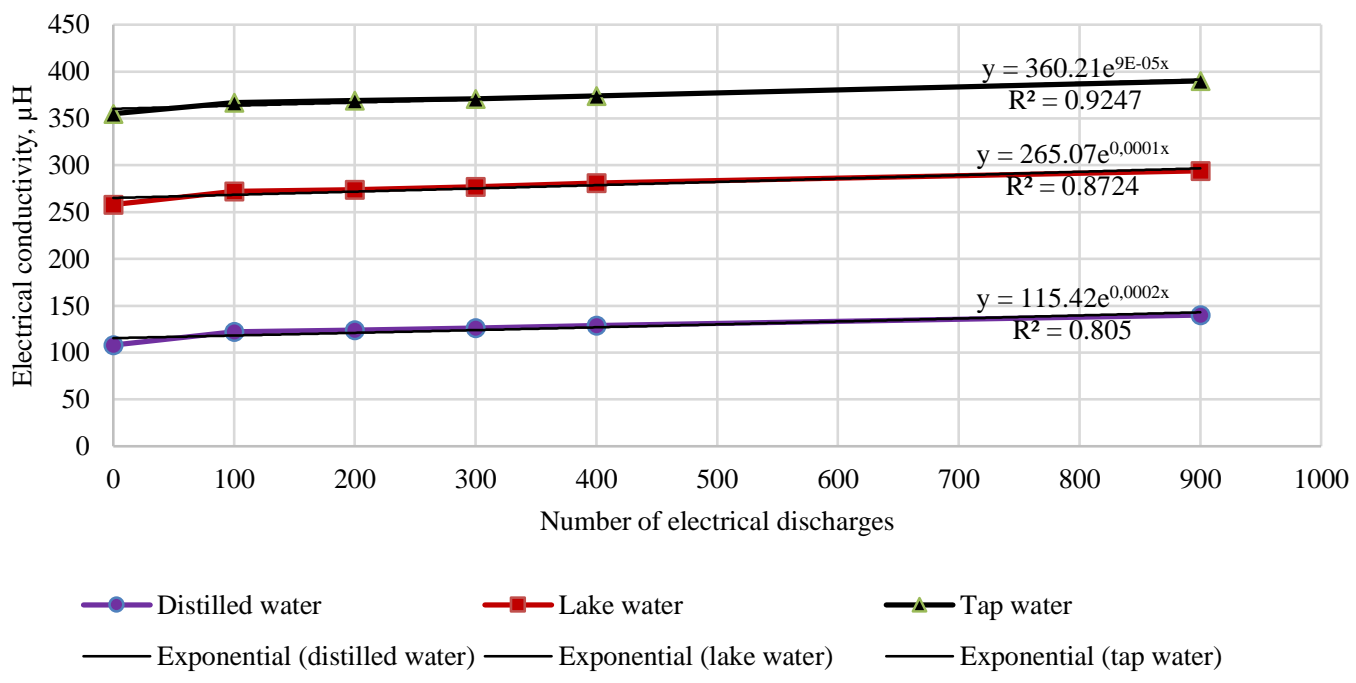

Figure 5. Dynamics of the specific conductivity of water at a voltage of $50 \mathrm{kV}$ 
The electrical conductivity of the water samples was measured directly in the container where the exposure took place, in the full volume of the water sample by immersing the electrical conductivity sensor of the ATLANT 1200 measuring instrument no later than 1 minute after the $\mathrm{EH}$ water treatment. The temperature was measured in the total volume of the treated water after mixing.

The curves constructed from the results of experimental studies are approximated by exponential functions and are described by the following empirical expressions with an approximation confidence value:

- at a pulse energy of $11.3 \mathrm{~kJ}$ for distilled water, $\mathrm{y}=112.44 \cdot \mathrm{e}^{0.0001 \mathrm{x}}, \mathrm{R}^{2}=0.7953$; for lake water, $\mathrm{y}=$ $264.53 \cdot e^{4 \mathrm{E}-0.5 \mathrm{x}}, \mathrm{R}^{2}=0.8539$; for tap water, $\mathrm{y}=356.54 \cdot \mathrm{e}^{4 \mathrm{E}-0.5 \mathrm{x}}, \mathrm{R}^{2}=0.96$;

- $\quad$ at a pulse energy of $72.2 \mathrm{~kJ}$ for distilled water, $\mathrm{y}=114.05 \cdot \mathrm{e}^{0.0002 \mathrm{x}}, \mathrm{R}^{2}=0.7837$; for lake water, $\mathrm{y}=$ $264.53 \cdot \mathrm{e}^{0.0001 \mathrm{x}}, \mathrm{R}^{2}=0.8539$; for tap water, $\mathrm{y}=359.39 \cdot \mathrm{e}^{8 \mathrm{E}-0.5 \mathrm{x}}, \mathrm{R}^{2}=0.9287$;

- $\quad$ at a pulse energy of $125.0 \mathrm{~kJ}$ for distilled water, $\mathrm{y}=115.42 \cdot \mathrm{e}^{0.0002 \mathrm{x}}, \mathrm{R}^{2}=0.8055$; for lake water, $\mathrm{y}=$ $265.07 \cdot \mathrm{e}^{0.0001 \mathrm{x}}, \mathrm{R}^{2}=0.8724$; for tap water, $\mathrm{y}=360.21 \cdot \mathrm{e}^{9 \mathrm{E}-0.5 \mathrm{x}}, \mathrm{R}^{2}=0.9247$.

A positive dynamic was revealed, generalizing the increase in the electrical conductivity of the water of the samples under study with an increase in the number of electrical discharges from 100 to 900 , regardless of the pulse energy of each technological mode. The choice of the number of spark discharges is due to the fact that at 900 discharges the minimum result of the EH-processing is achieved. This corresponds to the disinfection of water and an increase in the concentration of nitrogen compounds, that is, their conversion into easily digestible forms. This is confirmed by microbiological analyzes of water samples and studies of changes in the concentration of nitrogen in them.

A comparative analysis of the results of each of the three experiments showed that the percent increase in electrical conductivity is the higher, the higher the voltage source. At a voltage of $15 \mathrm{kV}$, the increase in electrical conductivity in percentage ratio is: $8.3 \%$ for distilled water, $3.5 \%$ for lake water, $3.9 \%$ for tap water. At a voltage of $38 \mathrm{kV}$, the increase in electrical conductivity in percentage is: $23.1 \%$ for distilled water, $12.0 \%$ for lake water, $8.5 \%$ for tap water. And at a voltage of $50 \mathrm{kV}$, the increase in electrical conductivity in percentage ratio is: $29.6 \%$ for distilled water, $14.0 \%$ for lake water, $9.9 \%$ for tap water.

The second process mode is considered to be the most preferable for further experimental studies from the point of view of safety, energy intensity and performance, while ensuring the parameters of which achieve a pulse energy of $72.2 \mathrm{~kJ}$. When operating at a voltage of $38 \mathrm{kV}$, a larger volume of water covered by the discharge is provided than at $15 \mathrm{kV}$, but smaller than at $50 \mathrm{kV}$ (the third process mode). The energy intensity of the EH-processing process increases simultaneously with the increase in the source voltage, therefore, when working with the parameters of the second process mode, the relative energy efficiency takes average intermediate values.

The change in the electrical conductivity of tap, distilled and lake water in the direction of increasing during the formation of electrical discharges is due to the formation of water bubbles and the structuring of water in terms of polarization of charged particles, that is, a change in their movement and activity. Increasing the temperature of all types of water samples after the EH-exposure is not more than $5{ }^{\circ} \mathrm{C}$ after 900 discharges, which will have no effect on the results of the EH-treatment in the preparation of the nutrient solution from water. Therefore, temperature is a minor factor that can be neglected. An increase in the electrical conductivity of water leads to a decrease in the resistance to the flow of electric current, therefore, the generation of electrical discharges will be carried out at a lower required energy. Consequently, the more discharges are given, the less they are required in dynamics for sparking.

The results of the experiments performed show the requirements for changes in the design of some nodes of the EH-installation to reduce the inductance and increase the capacitance. Thus, the mode of generating the maximum specific energy per unit time will be simulated, which is necessary to create the maximum steepness of the pulse front in order to ensure sufficient conditions for the electrohydraulic process to proceed. The results of experimental studies at various values of accumulated energy have scientific novelty, since they allow us to state that these energy values affect electrical conductivity, therefore, affect the result of EH-processing from the point of view of the formation of a nutrient solution from water.

\section{CONCLUSION}

Mathematical patterns are established and a logically justified correlation of the change in conductivity as a result of electrohydraulic processing is built.

The change in electrical conductivity of samples of tap, distilled and lake water in the direction of increasing during the electrohydraulic exposure is caused by the formation of water bubbles and the structuring of water in terms of polarization of charged particles, that is, a change in their movement and activity.

A scientific hypothesis has been advanced that electrical conductivity may serve as a criterion for evaluating the electrohydraulic treatment process with respect to the transfer of an aqueous working solution into a nutrient one. 


\section{REFERENCES}

[1] S. J. Lee, S. H. Ma, Y. C. Hong, M. C. Choi, "Effects of pulsed and continuous wave discharges of underwater plasma on Escherichia coli", Separation and Purification Technology, vol. 193, pp. 351-357, Mar 2018.

[2] B. R. Nussupbekov, A. K. Khassenov, D. Z. Karabekova, M. Stoev, A. Z. Beysenbek, Kazankap B.I., "New technology for the recovery of heat exchangers", Bulletin of the University of Karaganda-Physics, vol. 1, issue 85, pp. 67-72, 2017.

[3] D. Ruma, H. Hosano, T. Sakugawa, H. Akiyama, "The Role of Pulse Voltage Amplitude on Chemical Processes Induced by Streamer Discharge at Water Surface", Catalysts, vol. 8, issue 5, art. numb. 213, May 2018.

[4] A. N. Vasiliev, I. G. Ershova, A. A. Belov, V. N. Timofeev, V. Y. Uhanova, A. V. Sokolov, A. A. Smirnov, "Energysaving system development based on heat pump", Amazonia Investiga, vol. 7, issue 17, pp. 219-227, Nov-Dec 2018.

[5] J. S. Zheng, "Inactivation of Staphylococcus aureus in water by pulsed spark discharge", Scientific Reports, vol. 7, art. numb. 10311, Sep 2017.

[6] J. W. Feng, L. Jiang, D. Zhu, K. Z. Su, D. Y. Zhao, J. B. Zhang, Z. Zheng, "Dielectric barrier discharge plasma induced degradation of aqueous atrazine", Environmental Science and Pollution Research, vol. 23, issue 9, pp. 92049214, May 2016.

[7] A. G. Aksenov, A. I. Izmaylov, A. S. Dorokhov, A. V. Sibirev, "Onion bulbs orientation during aligned planting of seed-onion using vibration-pneumatic planting device", Inmateh-Agricultural Engineering, vol. 55, issue 2, pp. 6370, May-Aug 2018.

[8] L. Zhu, Z. H. He, Z.W. Gao, F. L. Tan , X. G. Yue, J. S. Chang, "Research on the influence of conductivity to pulsed arc electrohydraulic discharge in water", Journal of electrostatics, vol. 72, issue 1, pp. 53-58, Feb 2014.

[9] S. Imai, Y. Sakaguchi, T. Shirafuji, "Simultaneous generation of acidic and alkaline water using atmospheric air plasma formed in water", Japanese Journal of Applied Physics, vol. 57, issue 1, art. numb. 0102BC, Jan 2018.

[10] D. C. Bian, D. Yan, J. C. Zhao, S. Q. Niu, "Experimental Study of Pulsed Discharge Underwater Shock-Related Properties in Pressurized Liquid Water", Advances in Materials Science and Engineering, art. numb. 8025708, 2018.

[11] Y. Liu, Z. Y. Li, X. D. Li, G. Y. Zhou, H. Li, Q. Zhang, F. C. Lin, "Energy Transfer Efficiency Improvement of Liquid Pulsed Current Discharge by Plasma Channel Length Regulation Method", IEEE Transactions on Plasma Science, vol. 45, issue 12, pp. 3231-3239, part 2, Dec 2017.

[12] N. Ghaffarzadeh, H. Marefatjo, I. Soltani, F. Salahian, "Improvement Voltage Stability and Load Ability Enhancement by Continuation Power Flow and Bifurcation Theory", Indonesian Journal of Electrical Engineering and Informatics, vol. 1, No. 4, pp. 109-118, Dec 2013.

[13] Y. Kumari, A. Gupta, S. P. Bihari, R. N. Chaubey, B. Sehgal, "Performance and Analysis of Reactive Power Compensation by Unified Power Flow Controller", Indonesian Journal of Electrical Engineering and Informatics, vol. 3, No. 3, pp. 141-149, Sep 2015.

[14] S. W. Liu, Y. Liu, Y. J. Ren, F. C. Lin, Y. Liu, Y. K. Shen, "Influence of plasma channel impedance model on electrohydraulic shockwave simulation", Physics of plasmas, vol. 26, No. 2, art. numb. 023522, Feb 2019.

\section{BIOGRAPHY OF AUTHORS}

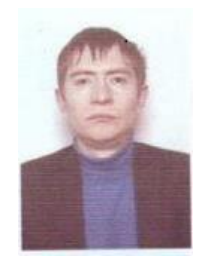

Alexander Anatolievich Belov - Dr.Sci. (Engineering), e-mail: belalexan85@gmail.com Federal State Budgetary Scientific Institution «Federal Scientific Agroengineering Center VIM», Moscow, Russia.

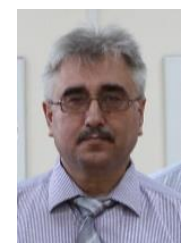

Alexey Nikolayevich Vasilyev - Dr.Sci. (Engineering), e-mail: vasilev-viesh@inbox.ru Federal State Budgetary Scientific Institution «Federal Scientific Agroengineering Center VIM», Moscow, Russia

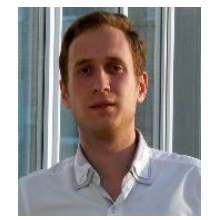

Andrey Anatolievich Musenko - postgraduate student, e-mail: argentios123@gmail.com Federal State Budgetary Scientific Institution «Federal Scientific Agroengineering Center VIM», Moscow, Russia 